\title{
Space and Sociability: Mapping Melbourne's City Square
}

\author{
Khalilah Zakariya, Nor Zalina Harun, Mazlina Mansor \\ Department of Landscape Architecture, \\ Kulliyyah of Architecture \& Environmental Design, \\ International Islamic University Malaysia, \\ P.O. Box 10, 50728 Kuala Lumpur, Malaysia \\ khalilah@iium.edu.my
}

\begin{abstract}
Public squares function as open spaces where people can conduct many activities and events in the city. The 'life' of squares evolves and changes according to the contemporary demands of the people. Learning about the evolution of the City Square in Melbourne, Australia, this study aims to analyse how its designs changed over the years in order to accommodate city life. This study employs spatial analysis to examine the relationships between the square's physical characteristics with people's activities. The findings reveal that square designs ought to meet evolving social, physical and environmental needs to cater for future requirements and lifestyles.
\end{abstract}

Keywords: Public space; spatial analysis; square; urban

eISSN: 2398-4279 @ 2016. The Authors. Published for AMER ABRA by e-International Publishing House, Ltd., UK.. This is an open access article under the CC BY-NC-ND license (http://creativecommons.org/licenses/by-ncnd/4.0/). Peer-review under responsibility of AMER (Association of Malaysian Environment-Behaviour Researchers), ABRA (Association of Behavioural Researchers on Asians) and CE-Bs (Centre for EnvironmentBehaviour Studies), Faculty of Architecture, Planning \& Surveying, Universiti Teknologi MARA, Malaysia.

https://doi.org/10.21834/ajqol.v1i2.28 


\subsection{Introduction}

Public squares play an essential role in enhancing the quality of urban life. The openness and robustness of squares often make them the centre of city events and social nodes. Squares are physical voids that offer breathing space amid the buildings. Good squares are sociable places (Whyte, 2003). This does not necessarily mean that strangers will always socialize with other strangers. It implies that people are comfortable to sit, 'hang out', or eat at the square in the public realm. Halprin (1981) explained that our experience of the city is shaped by the open spaces where people have the chance to engage with the communal city life. For squares, the social opportunities are enabled by dynamic relationships between space, form, and function and at times, unexpected factors. Mossop (2001, p. 11) suggested that if we look at how cities change over the years, 'it is no longer possible for us to rely on familiar urban typologies and principles'. However, we can still gather fundamental qualities that contribute to the success of city squares by examining how the space and form influence people's patterns of use.

In the case of Melbourne, squares were not initially included as part of the city's public space. Streets and parks scattered within the city serve as civic spaces for the public. It was not until the late sixties that the Melbourne City Council adopted the idea of having a public square (Reed, 2011). In 1968, grassed area primarily filled the square after rows of old buildings along Swanston Street were demolished. The city council then built a permanent square in 1976, which later opened to the public in 1980 (City of Melbourne, 2008). Acknowledging these changes, the aim of this study is to learn from the evolution of a square design in Melbourne and how the changes transformed people's utilization. For this purpose, we examine the City Square as a case study for an exploratory review. The objective of the study is first to unpack the physical characteristics of the square. Secondly, the study analyses how the spatial changes alter the square activities. Finally, we discuss the relationships between the physical characteristics and sociability of the City Square to construe lessons on the qualities of the square that contribute to a city's livability.

\subsection{Literature Review}

Public spaces are platforms where people can be a part of the public realm, which is different from the settings of their home, workplace or place of study. Mossop (2001) suggests that public culture and urban values are expressed in public spaces that encourage people to gather and socialize. Livable cities should accommodate diverse activities for the people by offering more desirable and attractive spaces. Vitality and sociability in public space means that people can carry out their activities in relative comfort and safety while interacting, engaging in spectacles and ceremonies, or just simply sitting or waiting (Das, 2008; Jalaladdini \& Oktay, 2012; Lynch, 1981; Mossop, 2001; Tibbalds, 2001). In the context of this study, sociability is defined as the ability for the public to 
become attracted to a space that allows them to conduct social and leisure activities, whether individually or as a group.

The designs of urban squares aim to provide open spaces for people that connect them to streets and buildings where they can gather and pause from the city's traffic and busy streets (Carmona, Heath, Oc, \& Tiesdell, 2003; Zucker, 2003). Like a good public space, squares should be sociable and robust enough to facilitate people's diverse activities. Francis (2010) describes that good public space should be well connected to other spaces rather than dividing, and offer opportunities for people to do spontaneous activities. As such, squares need to have qualities of permeability, legibility, opportunities and robustness to support different purposes (Lynch, 1981; Mossop, 2001). Over the years, numerous scholars, researchers and practitioners have studied urban squares to examine their typologies, functions, evolutions and contributions to the city. Studies similar to this are still very relevant today as cities across the globe dynamically grow and undergo change (de Arruda Campos, 2000; Jalaladdini \& Oktay, 2012; Nasution \& Zahrah, 2012; Vadiati \& Kashkooli, 2011). Most of these studies found that the roles of urban squares as a social space are still as important today as they were in history. However, it is important that we look at each square in relevance to their local context, physically and socially. This study builds upon the existing body of work in the area by interrogating how the design transformations of an urban square alter its sociability.

\subsection{Methodology}

Melbourne's City Square is selected as a case study because it has been redesigned after the lack of success of its first design scheme, which had affected the square's sociability. The methods comprise of analysis on existing reports and articles on the evolution of the City Square, and spatial analysis using maps and diagrams that draw the spaces and components of the square (Denscombe, 2007; Zeisel, 1984). We examine plans and sectional drawings to understand the relationships between the spatial characteristics of the square and people's activities, based on the secondary data gathered. Through the mapping, we identified six key aspects: the boundaries, surrounding context, connecting networks, visibility, connectivity, and the locations of the design components (de Arruda Campos, 2000; Whyte, 2003; Zucker, 2003). The data for the square's earlier design schemes is limited to the reference from secondary resources. This study acknowledges that detailed site survey and behavioural mapping can reveal a more in-depth understanding of the degrees of sociability of the square. 


\subsection{Results and Discussions}

\subsection{Role of context and location}

City Square is a plaza that is formerly the main civic centre and public space for the city of Melbourne. The surroundings of the square include the city's central street networks, which are Swanston Street and Collins Street. Its immediate context is the Westin Hotel, the iconic and historic St. Paul's Cathedral, the Regent Theatre and the Melbourne Town Hall. Fronting the square is a tram stop that is actively used by people to walk towards the adjoining streets, lane ways and buildings.

\subsection{Fragmented spaces and lack of sociability}

The first design scheme of the square was intended not as a large open space, but rather as fragmented spaces. The city concerned that the square would become a place for the public to do the gathering for protests. The design scheme consisted of a video screen, restaurants, a basement arcade shops and outdoor cafes (see Fig. 1). These spaces were connected by glazed canopy, a sunken amphitheatre, graffiti wall, reflecting pool, water wall and cascades and an open portion of the main square (Reed, 2011). The whole area was extensively paved by bluestones.

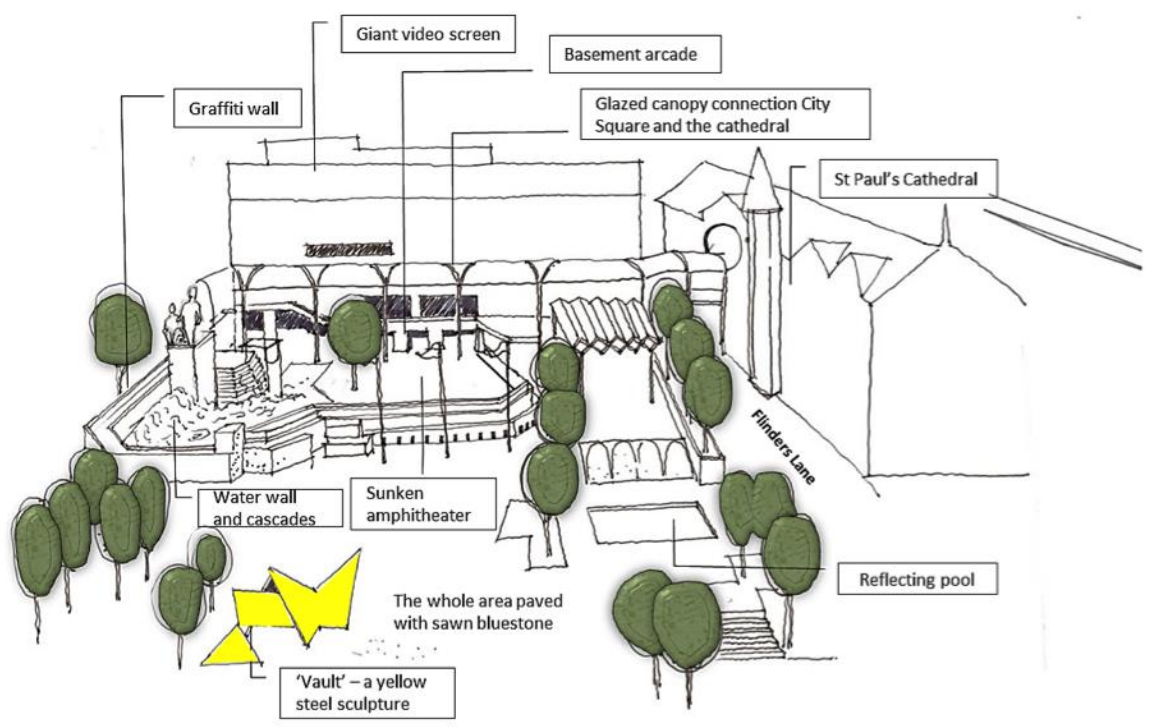

Figure 1: Spaces and components of the earlier design 
The giant video matrix that is placed on the building and the cascading water feature aimed to attract people towards the square. However, according to Reed (2011) and the City of Melbourne $(2008,2010)$, the water feature wall blocked the shops behind it, and the placement of the 'Vault', which is a yellow steel sculpture as public art on the edge of the square, blocked people's view towards the square from Swanston Street. (See Fig. 2-3).

Due to the fragmentation of spaces and obstructed visibility, the design of the square at that time fell short to meet the needs of people. According to Reed (2011) and the City of Melbourne $(2008,2010)$, among the factors that contributed to the square's lack of sociability, are:

i) The square failed to create a flexible space for public use because it was broken down into smaller spaces. This had disabled the opportunities for people to use the square as an open civic space.

ii) The adjacent shops, arcades and some of the public amenities were hidden because of the design components (water feature and sculpture) that blocked the people's visibility from the street.

iii) The City Square Shopping Mall was located relatively far from the pedestrian path along Swanson Street. Shopping malls are usually strong social nodes that can draw people into buildings. However, the blocked views and fragmented spaces discouraged pedestrians to walk across the wide square.

iv) The square was extensively paved with blue stone pavement, with only little patches of green areas. Lack of greens made it an uncomfortable place for people especially during summer. The glazed steel canopy and the hard surfaces increased glare and heat during hot summer days.

Since the square was equipped with the giant video screen and the cascading water feature in the same area, the public had complained about the level of noise that came from these components.

The early design of the City Square revealed the disconnectedness between the spaces and the people. Pragmatically, the proposed spaces and components (such as the sunken plaza, water features, sculpture and the video screen) had the potentials to activate the square as a vibrant social node. However, the overall design missed some of the qualities that can make a square more sociable through offering more open and comfortable spaces for the people, and better visibility and connections with its adjacencies. Over time, the hidden and unused areas became a target for vandalism (Reed, 2011). The square eventually decayed away from public use after twenty years. 


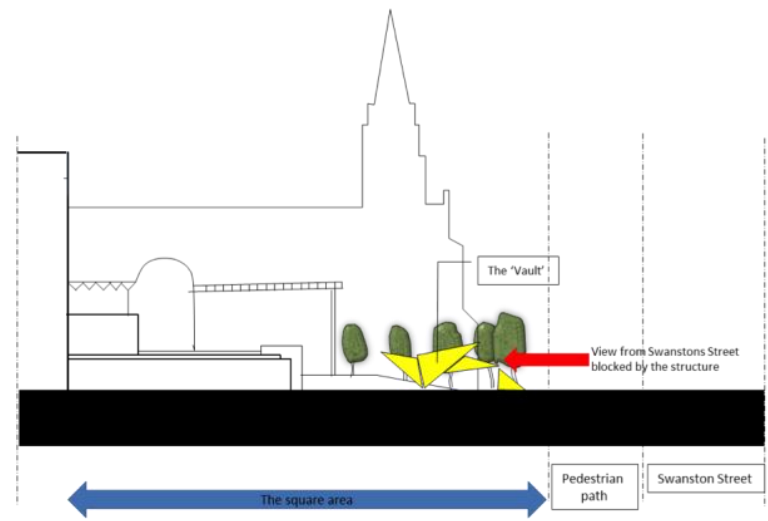

Figure 2: The placement of the sculpture blocked views towards the square from Swanston Street

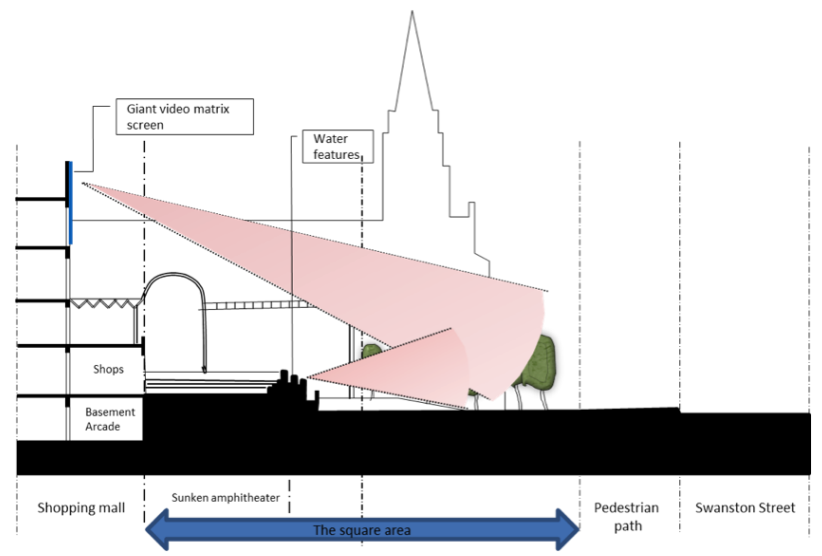

Figure 3: The placement of the video screen and water feature at the square

\subsection{Open spaces and increased sociability}

In between 1997 and 2000, the city council redeveloped the City Square by reducing half of its site (City of Melbourne, 2008). The new City Square was designed to be more open and less fragmented. By reducing the size of the original square and maintaining the ground level for pedestrians, the square is more visible and accessible from Swanston Street, Collins Street and Flinders Lane (City of Melbourne, 2008, 2010; Reed, 2011) (see Fig. 45). The ground level of the extended Westin Hotel and Apartments incorporated rows of shops and bars that are visible at the street level. 
The sunken plaza, water cascade and most of the bluestones pavement were removed and replaced with a sandy open space with benches and trees for people to sit. The square still had some change of levels, where the grassy patches are now raised up into a planter box that allow people to sit on the grass and along the edges.

A local café called Brunetti operated on one end of the square with outdoor seating. A water wall remains at the corner of Swanston Street and Collins Street, and the yellow sculpture was relocated to Batman Park. The sidewalk that stretches between the City Square and Swanston Street was planted with an avenue of trees.

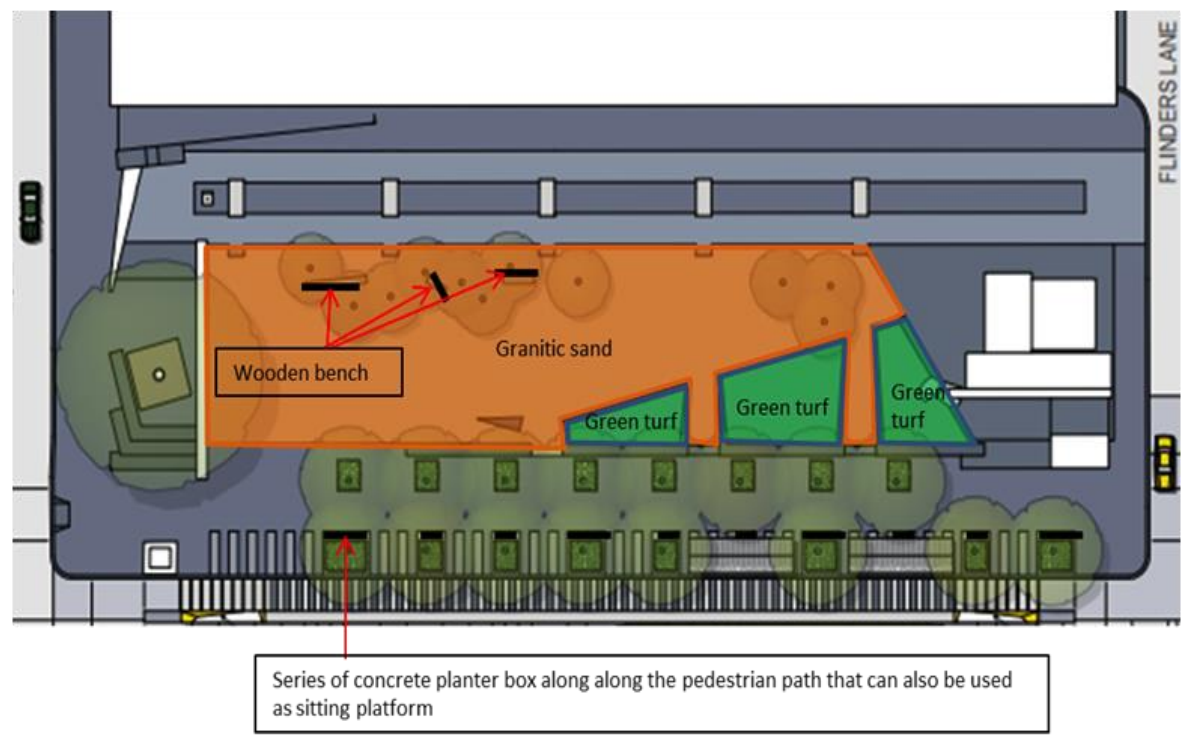

Figure 4: The plan of the transformed square design (Adapted from City of Melbourne, 2008)

By transforming the spaces and forms of the square and its components, the City Square gradually began to attract more people to use it as their public space. The following physical transformation strategies revitalized the square's function as a civic space.

i) The cafes on the ground level became a popular meeting spot for the locals and tourists. The visible social activities of people sitting, chatting and drinking coffee denoted that the square is a vibrant and active.

ii) The rows of trees along the sidewalk on the edge of the square soften the space and provide informal seating areas for people to relax or have a lunch.

iii) The new surfaces of the square that featured granitic sand and grass is more flexible to accommodate different activities in the local climate. The sandy area in 
the provides a safe platform for children to play and to hold temporary structures for events.

iv) The square is now often used for formal events such as the Christmas festival, fashion festival and special events because crowds of people can gather at the square compared to its previous fragmented spaces.

v) The square is easily reachable via trams that go through Swanson Street. People can stop directly at the street corner of the square.

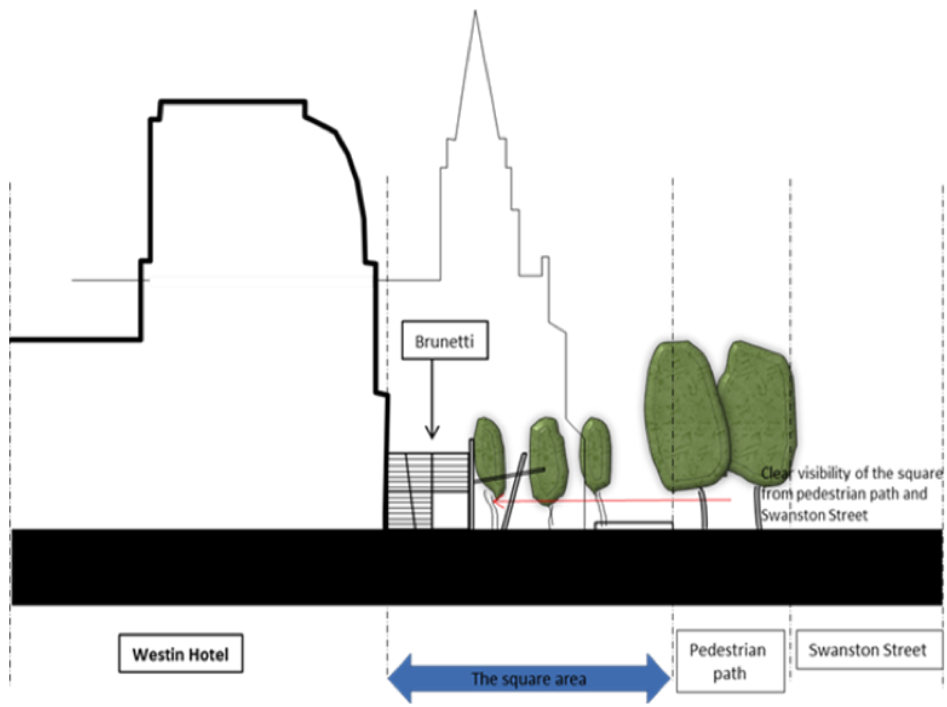

Figure 5: The width of the square was reduced and had more visibility and accessibility

\subsection{Spatial characteristics of urban square and sociability}

As one of the earliest urban open spaces in Melbourne, the inception of the City Square derived from the influences of political and social needs intersected with spatial outcomes. In the early design of the square, the city council was concerned that opening up a public space in the middle of the city might invite negative activities. The city council initially disregarded the notion that a square should function as a place for the public. As such, the design strategy was to discourage people from gathering in a large open space. The spaces were split into different levels and, as a result, they were not well integrated. The lack of visibility and connectivity between the square space and its adjacent buildings and street made the square unattractive to the public. The attempt to control people's activities at the square eventually led to the decay of the square's livability.

It was through the long history and experience of understanding the relationship between urban space and city life that the city council realized the potentials of the City 
Square. From the physical and social transformation strategies presented previously, we can construe that the life of the square lies in the people. As William Whyte writes, 'What attracts people most, it would appear, is other people' (Whyte, 2003, pp. 2.12-14). The City Square then evolved into a more sociable and vibrant public space. The changes made to the square design responded better to people's activities and created the City Square into an attractive public space. The city council reconciled the needs of people with their authoritative needs. This was facilitated by simple yet functional design that is robust to accommodate various activities. The new design also took into account how components and materials of the square influenced people's usage patterns in relation to the local climatic factors. The square is now more permeable to the adjacent shops, cafes, buildings and streets. This revealed to be another significant factor to the square's livability.

The needs to ensure that the crowd level at the square can be managed are still relevant in the new square design. With more porous spaces at the ground level, the square is clearly visible to the public from all sides, hence making it accessible, safe and much easier for the city council to control large crowds. The openness of the square and its close adjacency with other active spaces made the square a comfortable for people to be in the public as they know that their activities are visible to the public eye (Jacobs, 1961). This also enhanced the sociability of the square where people can be a part of the public realm.

The immediate context of the square played an essential role in supporting the life of the square. Historical, religious, administrative and commercial buildings surround the City Square. Most of these buildings are places that people go and use daily. The role of the square needs to complement the people's activities in the outdoors as a way of enhancing their quality of life in the city. Hence, it is vital for square designs to pay close attention to the social needs of its users. This might be as simple as providing spaces where people can sit and have their lunch to as complex as organizing events throughout the year. The sustainability of the square as a civic space relies on its flexibility and robustness. The square should be able to incorporate formal and informal activities. The City Square has thrived as a more intimate, active and flexible public space, simultaneously as a green space for the city.

\section{Conclusion}

This study demonstrates the use of spatial analysis, through plan and sectional diagrams drawn, as a method to examine how the physical and spatial qualities of the square have an effect on its function as a public space. From examining the relationships between the physical characteristics of the City Square with its sociability and livability as an urban space, we learn that a public square needs to have a strong connection with its people, physically, socially and environmentally. Lessons from the evolutions of the City Square insinuate that the role of a square is unique to its immediate context, microclimate and the culture of the locals. The findings and analysis revealed that the layout, spaces and 
components of the square indeed have an effect on the square's sociability. Placement of elements, the change of levels, provision of suitable open and green spaces, connectivity, and visibility were among the key criteria that contributed to the sociability of the square. However, it is critical that we also consider and discern the intangible qualities that make the square what it is. Essentially, the square is a space for people.

The City Square is just one example of many squares that have gone through physical changes that transformed it into an important social node for the city. Findings from reviewing the City Square and diagramming its spatial characteristics can contribute to the methods and criteria for evaluating and studying other squares. This denotes that public spaces like the square need to be understood at multiple scales and perspectives, such as how it horizontally and vertically relate to its adjacent spaces. Future studies on the City Square and other urban squares can map the patterns of users' activities, as well as the narratives of users that may unravel the meaning and attachment that they have towards the square. This study found that the spatial diagrams were essential in aiding the understanding on the spatial qualities of the square design. This exploratory review concludes that the design of urban open spaces may need to evolve from time to time, in line with the needs of the public.

\section{Acknowledgement}

This study was supported by the Research Endowment Fund from the International Islamic University Malaysia. The authors would like to thank Ms. Azlinda Kamarudzaman, Melbourne, Australia for her contributions in this research.

\section{References}

Carmona, M., Heath, T., Oc, T., \& Tiesdell, S. (2003). Public Places Urban Spaces: The Dimensions of Urban Design. Oxford: Architectural Press.

City of Melbourne. (2008). City Square Retrieved 14 May, 2013, from www.melbourne.vic.gov.au

City of Melbourne. (2010). Retrieved 14 May, 2013, from www.melbourne.vic.gov.au

Das, D. (2008). Urban quality of life: A case study of Guhawati. Social Indicators Research, 88(2), 297-310.

de Arruda Campos, M. B. M. (2000). Urban public spaces: A study of the relation between spatial configuration and use patterns. PhD, University College London, London.

Denscombe, M. (2007). The good research guide: for small-scale social research projects. Maidenhead: McGrawHill.

Francis, M. (2010). Mixed-life places. In T. Banerjee \& A. Loukaitou-Sideris (Eds.), Companion to Urban Design. New York: Routledge. 
Halprin, L. (1981). The collective perception of cities: We are an image of the landscape. In L. Taylor (Ed.), Urban Open Spaces. Washington: Smithsonian Institutions.

Jacobs, J. (1961). The death and life of great American cities. New York: The Modern Library.

Jalaladdini, S., \& Oktay, D. (2012). Urban public spaces and vitality: A socio-spatial analysis in the streets of two Cypriot towns. Procedia - Social and Behavioural Sciences, 35, 665-674.

Lynch, K. (1981). A Theory of Good City Form. Cambridge: MIT Press.

Mossop, E. (2001). Public space: Civilising the city. In E. Mossop \& P. Walton (Eds.), City Spaces: Art \& Design (pp. 10-26). Sydney: Craftsman House.

Nasution, A. D., \& Zahrah, W. (2012). Public open space's contribution to quality of life: Does privatisation matters? Asian Journal of Environment-Behaviour Studies, 3(9), 59-74.

Reed, D. (2011). Melbourne's City Square Retrieved 7 May, 2013, from http://architectureau.com/articles/citysquare/

Snape, D. (Producer). (2011, 7 May 2013). Melbourne's City Square. [Photography] Retrieved from http://architectureau.com/articles/city-square/\#img=1

Tibbalds, F. (2001). Making people-friendly towns: improving the public environment in towns and cities. London: Spon Press.

Vadiati, N., \& Kashkooli, A. M. S. (2011). Environmental sustainability of newly developed city squares in historic cities: Case study of Isfahan, Iran. Procedia Engineering, 21, 829-837.

Whyte, W. H. (2003). Social life of small urban space. In D. Watson, A. J. Plattus \& R. G. Shibley (Eds.), TimeSaver Standards for Urban Design. New York: McGraw-Hill.

Zeisel, J. (1984). Inquiry by design: Tools for environment behavior research. New York: Cambridge University Press.

Zucker, P. (2003). The square in space and time. In D. Watson, A. J. Plattus \& R. G. Shibley (Eds.), Time-saver standards for urban design. New York: McGraw-Hill. 